\begin{tabular}{|c|c|}
\hline $\begin{array}{c}\text { European Association for the } \\
\text { Development of Renewable Energies, } \\
\text { Environment and Power Quality }\end{array}$ & $\begin{array}{c}\text { International Conference on Renewable Energies and Power } \\
\text { Quality (ICREPQ'10) }\end{array}$ \\
Granada (Spain) 23, 24, 25 of March, 2010
\end{tabular}

\title{
Structural and optical study of titanium dioxide thin films elaborated by APCVD for application in silicon solar cells
}

\author{
D. Hocine ${ }^{1,2}$, M. Pasquinelli ${ }^{1}$, L. Escoubas ${ }^{1}$, P. Torchio ${ }^{1}$, A. Moreau ${ }^{1}$, MS. Belkaid ${ }^{2}$ \\ ${ }^{1}$ Aix-Marseille University, Institut Matériaux Microélectronique Nanosciences de Provence - \\ IM2NP CNRS UMR 6242 \\ Campus de Saint-Jérôme, Avenue Escadrille Normandie Niemen - Service 231, F-13397 Marseille Cedex 20, \\ France \\ E-mail : marcel.pasquinelli@univ-cezanne.fr, ludovic.escoubas@univ-cezanne.fr \\ ${ }^{2}$ Laboratory of Advanced Technologies of Genie Electrics (LATAGE) \\ Faculty of Electrical and Computer Engineering \\ Mouloud Mammeri University (UMMTO), BP 17 RP 15000, Tizi-Ouzou, Algeria \\ E-mail: dalilahocine@yahoo.fr, belkaid_ms@yahoo.fr
}

\begin{abstract}
In this work, titanium dioxide $\left(\mathrm{TiO}_{2}\right)$ thin films have been deposited on glass and monocrystalline silicon by Atmospheric Pressure Chemical Vapor Deposition (APCVD) technique using titanium tetrachloride $\mathrm{TiCl}_{4}$ as precursor. The structural, electrical and optical properties of the prepared $\mathrm{TiO}_{2}$ thin films were evaluated by Atomic Force Microscopy (AFM), Four Point Probe (FPP) and Spectroscopic Ellipsometry (SE), respectively. These properties were exploited for application of the $\mathrm{TiO}_{2}$ layers as antireflection coatings on monocrystalline silicon solar cells. Our experimental results show that the deposited $\mathrm{TiO}_{2}$ thin films were polycrystalline, homogenous, compact and relatively smooth. The measured average optical transmittance of the $\mathrm{TiO}_{2}$ films was about $85-90 \%$. From the ellipsometry analysis, the refractive index of our $\mathrm{TiO}_{2}$ thin films was found to be $n=2,25$ at the wavelength $\lambda=550 \mathrm{~nm}$, with a thickness of $56,2 \mathrm{~nm}$. These experimental results obtained by APCVD are in excellent agreement with the computed results of the $\mathrm{TiO}_{2}$ refractive index and thickness required for a high quality antireflection coating in industrial conditions. The obtained results demonstrate the real opportunity of the APCVD technique to prepare high quality antireflection coatings for crystalline solar cells. This indicates that the APCVD antireflection coatings may have a high potential industrial application.
\end{abstract}

Keywords: Titanium dioxide, APCVD, structural properties, optical properties, AFM, Ellipsometry, FourPoint Probe.

\section{Introduction}

Titanium dioxide $\left(\mathrm{TiO}_{2}\right)$ in thin films form has several properties that make it a material of interest for lots of applications. Indeed, $\mathrm{TiO}_{2}$ films can be used as coating in anticorrosive protection, as catalysts in chemical industry and environmental purification phenomena. $\mathrm{TiO}_{2}$ thin films have excellent electrical and optical properties, such as a high refractive index [1], [2] and excellent transmittance in the visible and near IR region of the solar spectrum [3], [4]. Since $\mathrm{TiO}_{2}$ is highly transparent, it acts like a window for the transmission of solar radiations. Due to its interesting optical properties, these films have been widely used as antireflection coatings (ARC).

High quality antireflection coatings are required for the realization of high performance solar cells. One of the optical requirements for antireflection coating is high refractive index. This characteristic can be achieved by optimization of the film preparation technique. Several techniques have been developed for elaborating the $\mathrm{TiO}_{2}$ thin films [5], [6], [7], [8]. Among them, atmospheric pressure chemical vapor deposition or APCVD is one of the most attractive, as it is known to be a low cost process giving high density stoichiometric and uniform films [9]. Moreover, it is especially 
applicable to large area, continuous deposition, as required for growth on glass or crystalline silicon [9]. Due to its several advantages, CVD has become one of the main processing methods for the deposition of amorphous, monocrystalline and polycrystalline thin films and coatings for a wide range of applications.

In this work, $\mathrm{TiO}_{2}$ thin films were fabricated on glass and monocrystalline silicon substrates by APCVD from the reaction of titanium tetrachloride $\mathrm{TiCl}_{4}$ with oxygen. The structural, electrical and optical properties of the prepared $\mathrm{TiO}_{2}$ thin films were evaluated by Atomic Force Microscopy (AFM), Four-point probe (FPP) and Spectroscopic ellipsometry (SE), respectively. In the light of these results, these properties were exploited for application of the $\mathrm{TiO}_{2}$ layers as single-layer antireflection coatings (SLARC) on monocrystalline silicon solar cells.

According to [10], achieving low reflectance for monocrystalline silicon solar cells having $\mathrm{TiO}_{2}$ as antireflection coating, is possible when the refractive index of the $\mathrm{TiO}_{2}$ layer is equal to $\mathrm{n}=2,2$ at $\lambda=550 \mathrm{~nm}$ with an estimated thickness of 56,8 $\mathrm{nm}$ as illustrated in figure 1 . These values can be achieved experimentally by optimization of the film preparation conditions.

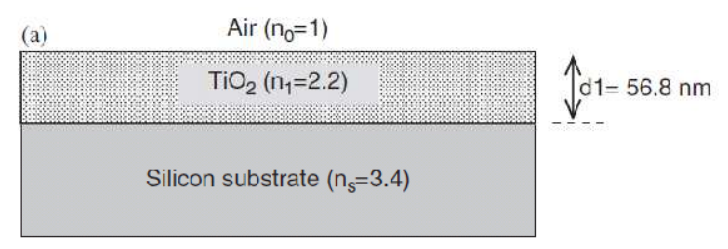

Figure1. Design diagram of a $\mathrm{TiO}_{2}$ single-layer antireflection coating [10].

\section{Experimental details}

\section{A. Preparation of $\mathrm{TiO}_{2}$ thin films}

In this work, we have deposited the titanium dioxide thin films on glass and monocrystalline silicon using the APCVD technique. The titanium tetrachloride $\mathrm{TiCl}_{4}$ (liquid) was used as the main precursor to form the titanium dioxide films.

The APCVD equipments consists of a Pyrex glass reactor with three inlets (for $\mathrm{TiCl}_{4}, \mathrm{O}_{2}$ and $\mathrm{N}_{2}$ ), and a chemical vapor precursor supply system. The CVD reactor consists of a reaction chamber equipped with a substrate holder, and a heating system with temperature control.

The glass and silicon substrates were washed successively in acetone, alcohol and distilled water to obtain clean surfaces which were dried before being placed in the reactor.

The $\mathrm{TiCl}_{4}$ liquid precursor was heated in a tube connected to the reactor. The $\mathrm{TiCl}_{4}$ vapor was transported into the reactor by oxygen as a carrier gas. The formation of the $\mathrm{TiO}_{2}$ films is due to the reaction of $\mathrm{TiCl}_{4}$ vapor with oxygen at the surface of the sample as follows:

$$
\mathrm{TiCl}_{4}(g)+\mathrm{O}_{2}(g) \rightarrow \mathrm{TiO}_{2}(S)+2 \mathrm{Cl}_{2}(g)
$$

A nitrogen gas $\left(\mathrm{N}_{2}\right)$ was injected into the chamber during the reaction in order to avoid undesirable oxidation of silicon at high temperature and to obtain a good uniformity of the films.

The CVD system being an "open" reactor, the resulting gases after deposition $\left(\mathrm{Cl}_{2}\right.$ in this case) were removed from the reactor.

A range of films were then grown at the deposition temperature of $450^{\circ} \mathrm{C}$ during $15 \mathrm{~min}$ and the oxygen pressure of 1 bar. Film thickness was controlled directly by deposition time. The deposited $\mathrm{TiO}_{2}$ films on silicon and glass substrates at $450^{\circ} \mathrm{C}$ were then annealed at $450^{\circ} \mathrm{C}$ for a period of 1 hour.

\section{B. Characterization methods}

The surface morphology of the films was studied by Atomic Force Microscopy using the AFM apparatus of NT-MDT Solver (France) operating in the air at ambient conditions. Samples topography was imaged by scanning in the non-contact (NCAFM) mode at resonant frequency of $310,75 \mathrm{kHz}$ and a scan rate of $1 \mathrm{~Hz}$. For comparison, the AFM measurements were also performed on bare silicon served as substrate and its RMS surface roughness was given. Roughness analysis and grain size measurements were performed using the Nanoscope software: "Nova".

The optical properties of the deposited $\mathrm{TiO}_{2}$ thin films were studied on the basis of the spectrophotometric measurements of the transmittance using the UV-VIS-IR 
"spectrophotometer 0306029S1" in the wavelength range of 300-800 $\mathrm{nm}$.

The refractive index of the prepared $\mathrm{TiO}_{2}$ films was evaluated by ellipsometry measurements using the "WINELLI_II 2.2.0.6" ellipsometer ("SOPRA" software). The thickness of the $\mathrm{TiO}_{2}$ layers was measured by AFM and ellipsometry for comparison.

The four-point probe (FPP) "KEITHLEY 236/237 TUTORIAL" in the linear probes configuration was used to measure the electrical resistivity of the prepared $\mathrm{TiO}_{2}$ films. Once the probes were in contact with the surface, a constant current was passed through the outer pins while the corresponding voltage drop was measured across the inside pins. In this work, currents of 1-2 mA were employed.

\section{Results and discussion}

\section{A. Morphological studies}

Figure 2, illustrates the two-dimensional (2D) AFM topographic images of a Si substrate and annealed thin film of $\mathrm{TiO}_{2}$ on $\mathrm{Si}$. The AFM images reveal the polycrystalline structure and the homogenous surface of the prepared $\mathrm{TiO}_{2}$ films. These films are dense, uniform and compact. They showed an excellent adhesion and passed the scotch Tape test with no visible degradation.

As estimated by AFM, the thickness of the $\mathrm{TiO}_{2}$ film on silicon substrate was found to be $56,2 \mathrm{~nm}$ which is confirmed by ellipsometry measurements.

The surface roughness can be quantitatively identified by the root-mean-squared roughness (rms. Roughness: $R_{r m s}$ ). $R_{r m s}$ is given by the standard deviation (S.D) of the data from AFM images, and determined using the standard definition as follows [11]:

$$
R_{r m s}=\sqrt{\frac{\sum_{n=1}^{N}\left(Z_{n}-\bar{Z}\right)^{2}}{N-1}}
$$

Where $Z_{n}$ represents the height of the ${ }^{\text {th }}$ data, $\bar{Z}$ is equal to the mean height of $Z_{n}$ in AFM topography, and $\mathrm{N}$ is the number of data.

From our analysis, we observed a regular roughness and uniform grain sizes which varied from $30 \mathrm{~nm}$ to
$34 \mathrm{~nm}$ for the as-deposited $\mathrm{TiO}_{2}$ films and after annealing at $450^{\circ} \mathrm{C}$ for $1 \mathrm{hr}$, respectively. These values are in good agreement with the mean crystallite size determined as a function of deposition temperature in $\mathrm{TiO}_{2}$ films, in other studies [12], [13].

In our work, the RMS surface roughness is determined from the area of $1,5 \mu \mathrm{m} \times 1,5 \mu \mathrm{m}$ for all samples.

As it can be seen in figure 2, the bare silicon is relatively smooth and its characteristic RMS roughness is 2,5 $\mathrm{nm}$. An RMS roughness of 5,1 was estimated for the as-deposited $\mathrm{TiO}_{2}$ films at $450^{\circ} \mathrm{C}$.

After annealing (at $450^{\circ} \mathrm{C}$ for $1 \mathrm{hr}$ ), we observed that the surface roughness increases to $\mathrm{R}_{\mathrm{rms}}=7,97$ $\mathrm{nm}$ due to an increase in grain sizes. According to [11], our $\mathrm{TiO}_{2}$ films exhibit values of RMS roughness similar to those obtained by B.S. Richards.

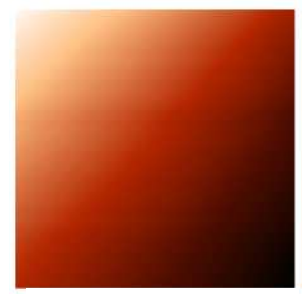

a) Si substrate

$\mathrm{R}_{\mathrm{rms}}=2,5 \mathrm{~nm}$

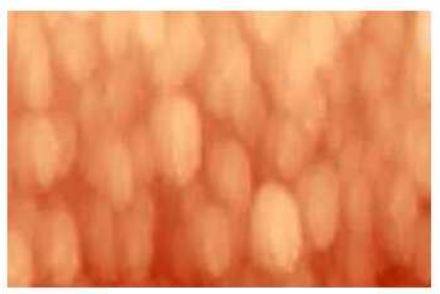

b) $\mathrm{TiO}_{2}$ on $\mathrm{Si}$ $\mathrm{R}_{\mathrm{rms}}=7,97 \mathrm{~nm}$
Figure 2: 2D-AFM images of:

a) Silicon substrate

b) $\mathrm{TiO}_{2}$ thin films deposited by APCVD at $450^{\circ} \mathrm{C}$ after annealing at $450^{\circ} \mathrm{C}$ for $1 \mathrm{hr}$.

\section{B. Optical studies}

\section{B.1. Optical transmittance}

Information concerning optical transmittance is important for evaluating the optical performance of the $\mathrm{TiO}_{2}$ thin films. The optical transmittance spectrum of the $\mathrm{TiO}_{2}$ films deposited on glass at $450^{\circ} \mathrm{C}$ and annealed at $450^{\circ} \mathrm{C}$ for $1 \mathrm{hr}$ is shown in figure 3 .

As it can be seen, the $\mathrm{TiO}_{2}$ films are optically transparent.

At the wavelength $350 \mathrm{~nm}$, the transmittance of the deposited film was found to be $32 \%$. A similar value was obtained by [14] for $\mathrm{TiO}_{2}$ films using the APCVD technique. 
The maximum transmittance obtained in this work for the $\mathrm{TiO}_{2}$ films was estimated to $90 \%$ (at $\lambda=800$ $\mathrm{nm}$ ) which is in good agreement with the calculated transmittance into the $\mathrm{TiO}_{2}$ films given by [15] as shown in table 1 . The presence of the interference peaks in the transmission spectrum of $\mathrm{TiO}_{2}$ films was also observed and clearly explained by [5].

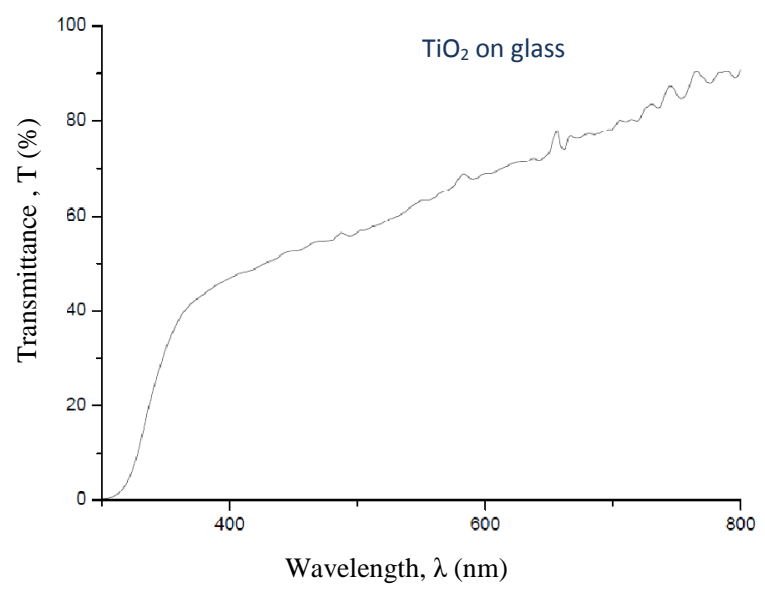

Figure 3. Optical transmittance spectrum of $\mathrm{TiO}_{2}$ thin film on glass.

TABLE 1: Transmittance results comparison on $\mathrm{TiO}_{2}$ thin films.

\begin{tabular}{|c|c|c|}
\hline Wavelength $\lambda$ & $\begin{array}{c}\text { Transmittance T } \\
\text { Experimental results } \\
\text { obtained in this work }\end{array}$ & $\begin{array}{c}\text { Transmittance T } \\
\text { Simulation results } \\
\text { given by [15] }\end{array}$ \\
\hline $800 \mathrm{~nm}$ & $90,2 \%$ & $90 \%$ \\
\hline
\end{tabular}

\section{B.2. Ellipsometry}

The estimated variation of the refractive index versus wavelength for the deposited $\mathrm{TiO}_{2}$ thin film on silicon substrate, and the corresponding best fit 2D graph are shown in figures 4 and 5 respectively. As mentioned above, the $\mathrm{TiO}_{2}$ film thickness was $56,2 \mathrm{~nm}$.

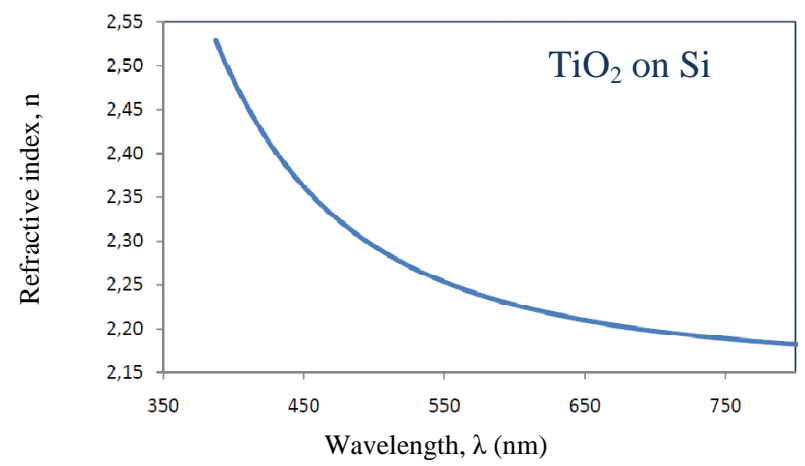

Figure 4. The variation of refractive index $\mathrm{n}$ versus the wavelength $\lambda$ for $\mathrm{TiO}_{2}$ Thin film deposited on $\mathrm{Si}$ at $450^{\circ} \mathrm{C}$ after annealing at $450^{\circ} \mathrm{C}$ for $1 \mathrm{hr}$.
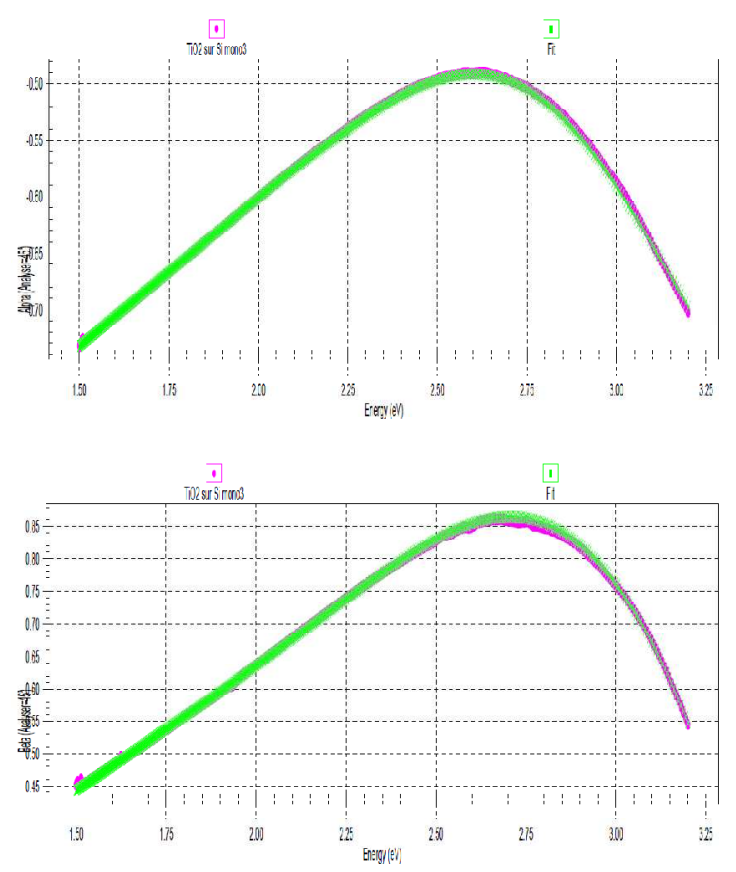

Figure 5. The corresponding best fit 2D graph

In this work, the refractive index of our $\mathrm{TiO}_{2}$ film was found to be $n=2,25$ at the wavelength $\lambda=550$ $\mathrm{nm}$ which is in excellent agreement with the literature values for $\mathrm{CVD} \mathrm{TiO}_{2}$ films illustrated (by the dotted horizontal line) in figure 6.

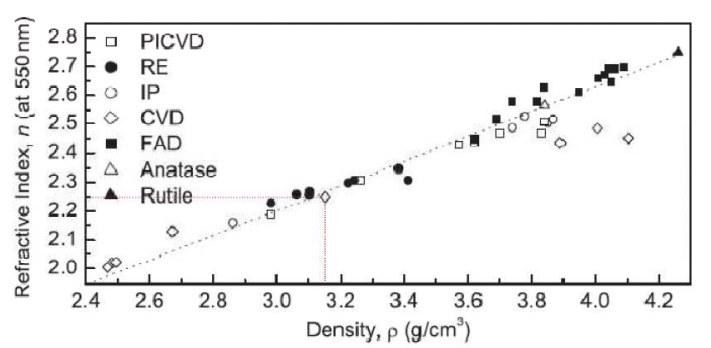

Figure 6. A linear relationship between values of $\mathrm{TiO}_{2}$ film density and refractive index is observed for many films reported in the literature. (The dotted horizontal line shows the refractive index at $550 \mathrm{~nm}$ for the $\mathrm{TiO}_{2}$ films elaborated by CVD [16]).

A decrease of the refractive index from $n=2,52$ to $\mathrm{n}=2,18$ with increased wavelengths between 390 and $800 \mathrm{~nm}$, was observed (figure 4).

To estimate the $\mathrm{TiO}_{2}$ film density $\rho$ in $\left(\mathrm{g} / \mathrm{cm}^{3}\right)$, the expression used is given below [16]:

$$
\dot{\rho}=\frac{n_{f}-0,91933}{0,42751}
$$

Additionally, the porosity $\varphi$ (the volume of pores per volume of film) of the $\mathrm{TiO}_{2}$ film depends on the refractivity of the film layer. It can be estimated by the equation (3) [16], [17], [18]: 


$$
\varphi=\left(1-\frac{n_{f}^{2}-1}{n_{d}^{2}-1}\right) \times 100(\%)
$$

Where $n_{f}$ is the refractive index of the $\mathrm{TiO}_{2}$ film, and $n_{d}$ is the refractive index of pore free anatase $\mathrm{TiO}_{2}$ which is found in the literature equal to 2,52 at $550 \mathrm{~nm}$ [17].

In this study, the density of the deposited $\mathrm{TiO}_{2}$ film is calculated using equation (2) at $550 \mathrm{~nm}$ and is found to be $\rho=3,11 \mathrm{~g} / \mathrm{cm}^{3}$.

The porosity of the prepared $\mathrm{TiO}_{2}$ film which is assumed to be homogenous, is determined using equation (3) and found to be $\varphi=24 \%$.

TABLE 2: Ellipsometric results comparison.

\begin{tabular}{|c|c|c|c|}
\hline $\begin{array}{c}\text { Deposition } \\
\text { technique }\end{array}$ & $\begin{array}{c}\text { Deposition } \\
\text { temperature }\end{array}$ & $\begin{array}{c}\text { Refractive index } \\
\text { obtained in this } \\
\text { work }^{\mathrm{a}} \text { at } 600 \mathrm{~nm} .\end{array}$ & $\begin{array}{c}\text { Refractive index } \\
\text { given by [16 }]^{\mathrm{b}} \text { at } \\
600 \mathrm{~nm} .\end{array}$ \\
\hline APCVD & $450^{\circ} \mathrm{C}$ & 2,2 & 2,19 \\
\hline
\end{tabular}

${ }^{\mathrm{a}} \mathrm{The} \mathrm{TiO}_{2}$ thin films are deposited from $\mathrm{TiCl}_{4}$ at $450^{\circ} \mathrm{C}$ and then annealed at $450^{\circ} \mathrm{C}$ for 1 hour.

${ }^{\mathrm{b}} \mathrm{The} \mathrm{TiO}_{2}$ thin films are deposited from TPT $\mathrm{Ti}\left(\mathrm{OC}_{3} \mathrm{H}_{7}\right)_{4}$ at $450^{\circ} \mathrm{C}$ and annealed at $1000^{\circ} \mathrm{C}$ for 1 hour.

As shown in table 2, the good agreement reached between our experimental values of refractive index and those obtained by B.S. Richards [16] in spite of the difference in the annealing temperature can be explained in terms of the growth rate of the films, which was faster in the case of TPT than the $\mathrm{TiCl}_{4}$, as it was observed by Philip Evants [12].

\section{Electrical properties}

As mentioned above, the electrical resistivity of the deposited $\mathrm{TiO}_{2}$ films was estimated with the Fourpoint probe, using the relation (5):

$$
\rho=\frac{\pi}{\operatorname{Ln2}}\left(\frac{\Delta V}{I}\right) e
$$

Or

$$
\rho=4,53\left(\frac{\Delta V}{I}\right) e
$$

Where $\Delta V$ is the measured voltage, $I$ the applied current and $e$ is the thickness of the $\mathrm{TiO}_{2}$ film which is equal to $56,2 \mathrm{~nm}$.
The sheet resistance of the layer is then given by:

$$
R_{\square}=4,53 \frac{\Delta V}{I}
$$

In this work, the electrical resistivity of the deposited $\mathrm{TiO}_{2}$ films at $450^{\circ} \mathrm{C}$ annealed at $450^{\circ} \mathrm{C}$ for $1 \mathrm{hr}$, was found to be $\rho=1,7 \times 10^{-3} \Omega . \mathrm{cm}$, which is in good agreement with the $\mathrm{TiO}_{2}$ resistivity estimated by Ginley [19].

The sheet resistance of our $\mathrm{TiO}_{2}$ films was equal to $R_{\square}=303 \Omega / \square$.

It is interesting to note that the good conductivity of our $\mathrm{TiO}_{2}$ films is very compatible with the conductivity requirements of TCO (Transparent Conducting Oxide) for application as ARC in silicon solar cells.

\section{Application to antireflection coating}

The above results show the possibility to fabricate $\mathrm{TiO}_{2}$ layers with the optimal optical qualities required for antireflection coating, using the APCVD technique.

TABLE 3: Comparison between the experimental and calculated results of two parameters: refractive index and thickness of $\mathrm{TiO}_{2}$ layers for application as ARC.

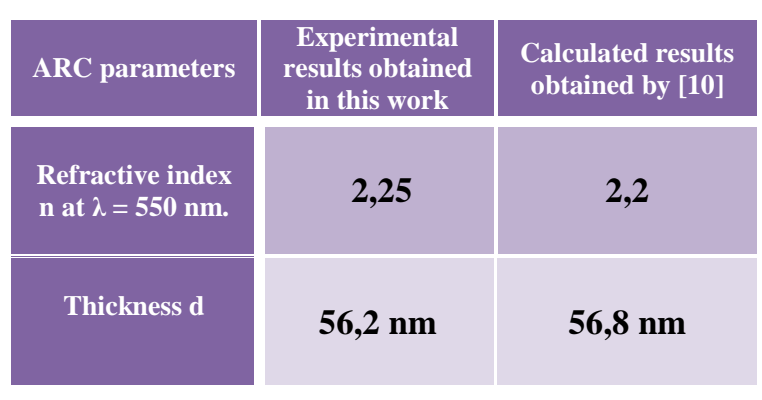

As shown in table 3, an excellent agreement is reached between our experimental results and calculated results given by Shui-Yang Lien [10] for $\mathrm{TiO}_{2}$ single-layer antireflection coating (SLARC) on monocrystalline silicon solar cells. 


\section{Conclusion}

In this work, we demonstrated by AFM studies that the $\mathrm{TiO}_{2}$ thin films produced by APCVD technique from $\mathrm{TiCl}_{4}$ as precursor at $450^{\circ} \mathrm{C}$ were polycrystalline, homogenous, compact and relatively smooth. The surface roughness of these films was observed to increase after annealing.

From the spectrophotometric measurements, the deposited $\mathrm{TiO}_{2}$ thin films were optically transparent having an average optical transmittance of about $85-90 \%$.

The ellipsometry analysis shows the good optical properties of our $\mathrm{TiO}_{2}$ thin films having a refractive index of 2,25 at $\lambda=550 \mathrm{~nm}$ with corresponding thickness of $56,2 \mathrm{~nm}$. These experimental results obtained by APCVD are in excellent agreement with the calculated results of the $\mathrm{TiO}_{2}$ refractive index and thickness required for a high quality antireflection coating in industrial conditions.

Combining the high quality films deposition, lower cost processing, we believe that the APCVD elaborated $\mathrm{TiO}_{2}$ antireflection coatings have good promise and potential to meet the goal of largescale industrial applications.

\section{Acknowledgement}

D. Hocine would like to thank the IM2NP Laboratory (Marseille, France) for providing the AFM, Four-point probe and spectroscopic ellipsometer equipments and is grateful to Profs. L. Escoubas and M. Pasquinelli for the support and for creating excellent conditions for collaboration in this field of research.

The author would also like to thank Dr. Alain Portavoce for his assistance in the AFM experiments. His contribution to this work is highly appreciated.

The author was also thankful to the LATAGE Laboratory (Tizi-Ouzou, Algeria) for providing the APCVD equipments and is grateful to Prof., MS. Belkaid for his support and assistance during the APCVD experiments.

\section{References}

[1] Lianchao Sun, Ping Hou, "Spectroscopic ellipsometry study on e-beam deposited titanium dioxide films", Thin Solid Films (2004), 525-529.

[2] B.S. Richards, S.F. Rowlands, "Potential cost reduction of buried-contact solar cells through the use of titanium dioxide thin films", Solar Energy 76 (2004) 269-276.

[3] P.S. Shinde, S.B. Sadale, "Properties of spray deposited titanium dioxide thin films and their application in photoelectrocatalysis", Solar Energy Materials \& Solar Cells 92 (2008) 283-290.

[4] R. Zallen , M.P. Moret, "The optical absorption edge of brookite $\mathrm{TiO}_{2}$ ", Solid State Communications 137 (2006) $154-157$.

[5] P.S. Shinde, C.H. Bhosale, "Properties of chemical vapour deposited nanocrystalline $\mathrm{TiO}_{2}$ thin films and their use in dye-sensitized solar cells", J. Anal. Appl. Pyrolysis 82 (2008) 83-88.

[6] Masayuki Okuya, Koji Nakade, " Porous $\mathrm{TiO}_{2}$ thin films synthesized by a spray pyrolysis deposition (SPD) technique and their application to dye-sensitized solar cells", Solar Energy Materials \& Solar Cells 70 (2002) 425-435.

[7] A. Bendavid, P.J. Martin, "Deposition and modification of titanium dioxide thin films by filtered arc deposition", Thin Solid Films 360 (2000) 241-249.

[8] C. Legrand-Buscema, C. Malibert, "Elaboration and characterization of thin films of $\mathrm{TiO}_{2}$ prepared by sol-gel process", Thin Solid Films 418 (2002) 79-84.

[9] B. Vallejo, M. Gonzalez-Manas, "Characterization of $\mathrm{TiO}_{2}$ deposited on textured silicon wafers by atmospheric pressure chemical vapour deposition", Solar Energy Materials \& Solar Cells 86 (2005) 299-308.

[10] Shui-Yang Lien, Dong-Sing Wuu, "Tri-layer antireflection coatings $\left(\mathrm{SiO}_{2} / \mathrm{SiO}_{2}-\mathrm{TiO}_{2} / \mathrm{TiO}_{2}\right)$ for silicon solar cells using a sol-gel technique", Solar Energy Materials \& Solar Cells 90 (2006) 2710-2719.

[11] B.S. Richards, "Novel uses of titanium dioxide for silicon solar cells", PhD thesis, University of New South Wales, Australia, 2002.

[12] Philip Evans, Martyn E. Pemble, "Precursor-Directed Control of Crystalline Type in Atmospheric Pressure CVD Growth of $\mathrm{TiO}_{2}$ on Stainless Steel", Chem. Mater. 18 (2006), 5750-5755.

[13] Cullity, B. D. Elements of X-Ray Diffraction; Prentice Hall: Upper Saddle River, NJ 2001.

[14] Yu Guo, Xi-wen Zhang, "Structure and properties of nitrogen-doped titanium dioxide thin films grown by atmospheric pressure chemical vapor deposition", Thin Solid Films 515 (2007) 7117-7121.

[15] Yasuhiro Tachibana, Hitomi Y. Akiyama, "Optical simulation of transmittance into a nanocrystalline anatase $\mathrm{TiO}_{2}$ film for solar cell applications", Solar Energy Materials \& Solar Cells 91 (2007) 201-206.

[16] B.S. Richards, "Single-material $\mathrm{TiO}_{2}$ double-layer antireflection coatings", Solar Energy Materials \& Solar Cells 79 (2003) 369-390.

[17] N.R. Mathews, Erik R. Morales, " $\mathrm{TiO}_{2}$ thin films Influence of annealing temperature on structural, optical and photocatalytic properties", Solar Energy 83 (2009) 1499-1508.

[18] R. Mechiakh, F. Meriche, " $\mathrm{TiO}_{2}$ thin films prepared by solgel method for waveguiding applications: Correlation between the structural and optical properties", Optical Materials 30 (2007) 645-651.

[19] D.S. Ginley and M.L. Knotek, "Hydrogen in titanium dioxide photoanodes", Journal of the Electrochemical Society, 126 (1979), 2163-2166. 